OPEN ACCESS

Edited by:

Lucio Vilar,

Federal University of Pernambuco,

Brazil

Reviewed by:

Edward Raymond Laws,

Brigham and Women's Hospital,

Harvard Medical School,

United States

Mirtha Adriana Guitelman,

Durand Hospital, Argentina

*Correspondence:

Maria M. Pineyro

mercepin@gmail.com

orcid.org/0000-0003-2083-7839

Specialty section:

This article was submitted to Pituitary Endocrinology,

a section of the journal

Frontiers in Endocrinology

Received: 12 December 2018

Accepted: 12 February 2019

Published: 04 March 2019

Citation:

Pineyro MM, Redes L, De Mattos S, Sanchez L, Brignardello E, Bianchi V,

Ems V, Centurión D and Viola M (2019) Factitious Cushing's Syndrome: A Diagnosis to Consider When Evaluating Hypercortisolism.

Front. Endocrinol. 10:129.

doi: 10.3389/fendo.2019.00129

\section{Factitious Cushing's Syndrome: A Diagnosis to Consider When Evaluating Hypercortisolism}

\author{
Maria M. Pineyro ${ }^{1 *}$, Lia Redes ${ }^{2}$, Sylvana De Mattos ${ }^{2}$, Luciana Sanchez ${ }^{1}$, \\ Estefania Brignardello ${ }^{1}$, Virginia Bianchi ${ }^{2}$, Vanessa Ems ${ }^{2}$, Dardo Centurión ${ }^{3}$ and \\ Marcelo Viola ${ }^{4}$ \\ ${ }^{1}$ Clínica de Endocrinología y Metabolismo, Facultad de Medicina, Hospital de Clínicas, Universidad de la República, \\ Montevideo, Uruguay, ${ }^{2}$ Clínica Psiquiátrica, Facultad de Medicina, Hospital de Clínicas, Universidad de la República, \\ Montevideo, Uruguay, ${ }^{3}$ Departamento de Anatomía Patológica, Facultad de Medicina, Hospital de Clínicas, Universidad de \\ la República, Montevideo, Uruguay, ${ }^{4}$ Clínica Quirúrgica 1, Facultad de Medicina, Hospital Pasteur, Universidad de la \\ República, Montevideo, Uruguay
}

Factitious Cushing's syndrome is exceptionally rare. The diagnosis is challenging due to the interference of exogenous corticosteroids with cortisol immunoassays. We present a case of a 26 year old female that presented with clinical and biochemical features of Cushing's syndrome. She denied any exogenous corticosteroid use. She had a suppressed ACTH level with normal adrenal glands on CT scans. There was a paradoxical increase of cortisol with a $100 \%$ rise in $24 \mathrm{~h}$ urinary free cortisol (UFC) during the Liddle's test suggestive of primary pigmented nodular adrenocortical disease (PPNAD). However, basal UFC levels were within normal values, interpreted as an intermittent variation of cortisol secretion maybe due to cyclic Cushing's. At this point a synthetic glucocorticoid serum screening was ordered, which was denied by the administrators because the test was not available in our hospital. A positron emission tomography (PET)-CT using 18 F-Flurodeoxyglucose did not show any uptake in the adrenal glands. With the diagnosis of probable primary pigmented nodular adrenocortical disease a unilateral right adrenelectomy was performed. Histopathological examination revealed normal adrenal gland. A synthetic glucocorticoid serum screen by liquid chromatography-tandem mass spectrometry (LC-MS/MS) sent to Mayo Clinic lab revealed high levels of serum prednisone and prednisolone. In conclusion, factitious Cushing's syndrome is an important diagnosis to consider in patients being evaluated for hypercortisolism. Discordant hormonal test results as well as normal findings on adrenal glands on CT scan should raise suspicion of this entity, and prompt measurement of synthetic corticosteroids using LC-MS/MS.

\footnotetext{
Keywords: hypercortisolism, Cushing's syndrome, factitious Cushing's syndrome, synthetic glucocorticoid screen, liquid chromatography-tandem mass spectrometry
}

\section{BACKGROUND}

Factitious disorder imposed on self is a psychiatric disorder characterized by intentional fabrication of physical or physiological symptoms and/or signs, without an obvious gain (DSM-5). In contrast to malingering, who fabricate symptoms for obvious external reward such as financial gain, avoiding military duty or work, the motivation of patients with factitious disorder is to receive medical attention. 
The surreptitious administration of several hormones has been reported, such as cathecholamine injection mimicking pheocromocytoma, insulin imitating insulinoma, and thyroid hormone ingestion feigning thyrotoxicosis (1-3). Exogenous ingestion of corticosteroids is the most common cause of Cushing's syndrome.

Reports of factitious Cushing's syndrome are extremely rare. In addition, the diagnosis is challenging due to interference of synthetic corticosteroids and their metabolites with cortisol immunoassays (4). We present a case of factitious Cushing's in which multiple investigations where done and a unilateral adrenelectomy was performed.

\section{CASE PRESENTATION}

A 26 year-old woman with diagnosis of orofacial granulomatosis was referred for the evaluation of possible Cushing's syndrome. She reported a $15-\mathrm{kg}$ weight gain and facial erythema. She had received prednisone for orofacial granulomatosis 2 years ago for 2 weeks prescribed by her dermatologist, but she denied any corticosteroid use thereafter. She denied any symptoms of hyperandrogenism or virilization such as acne, hirsutism, seborrhea, balding, or deepening of the voice. She had regular menstrual cycles and was not taking oral contraceptives. She had no history of diabetes or hypertension. Her family history included a brother who works as a nurse. Physical exam revealed a BMI of $22.4 \mathrm{~kg} / \mathrm{m}^{2}$, with no facial plethora or skin striae. No hirsutism, acne, spotty pigmentation, or skin myxomas were noted. Thyroid examination was normal. The clinical suspicion for Cushing's syndrome was low. We ordered a lowdose dexamethasone suppression test and reschedule the patient for a 3-month follow-up. At 3 months follow-up she had developed new symptoms such as proximal muscle weakness, facial plethora, and reddish purple striae. Physical examination revealed Cushingoid features with moon face, supraclavicular fat pads and facial plethora. In addition, reddish purple striae $>1 \mathrm{~cm}$ wide and proximal myopathy were noted.

Work-up revealed an 8 a.m., serum cortisol of $6 \mu \mathrm{g} / \mathrm{dl}$ after $1 \mathrm{mg}$ overnight dexamethasone suppression test (DST). Further work-up showed two consecutive elevated 24-h urinary free cortisol (UFC) (>510 $\mu \mathrm{g} /$ day and $>485 \mu \mathrm{g} /$ day, normal 20-90). The morning plasma adrenocorticotropic hormone (ACTH) was suppressed ( $<1 \mathrm{pg} / \mathrm{ml}$, normal 7.2-63.3). These findings were consistent with an ACTH-independent Cushing's syndrome. She had normal complete blood count, LFT, KFT, and serum electrolytes. Lipid profile showed total cholesterol of $213 \mathrm{mg} / \mathrm{dl}$, triglycerides of $90 \mathrm{mg} / \mathrm{dl}, \mathrm{HDL}-\mathrm{C}$ of $49 \mathrm{mg} / \mathrm{dl}$, and LDL-C of 159 $\mathrm{mg} / \mathrm{dl}$. She was diagnosed with impaired fasting glucose (FPG of 104 and $109 \mathrm{mg} / \mathrm{dl}$ ). Adrenal computed tomography (CT) scan showed no nodules or hyperplasia (Figure 1). With the suspicion of primary pigmented nodular adrenocortical disease a Liddle's test was ordered. During Liddle's test of 6 days (2 days of baseline collection, 2 days of $0.5 \mathrm{mg}$ of dexamethasone orally every $6 \mathrm{~h}$, and 2 days of $2 \mathrm{mg}$ orally every $6 \mathrm{~h}$ ) urinary cortisol increased from 71 to $413 \mu \mathrm{g} /$ day. Basal urine free cortisol levels were within normal values $(20-100 \mu \mathrm{g} /$ day $)$. It was interpreted as an

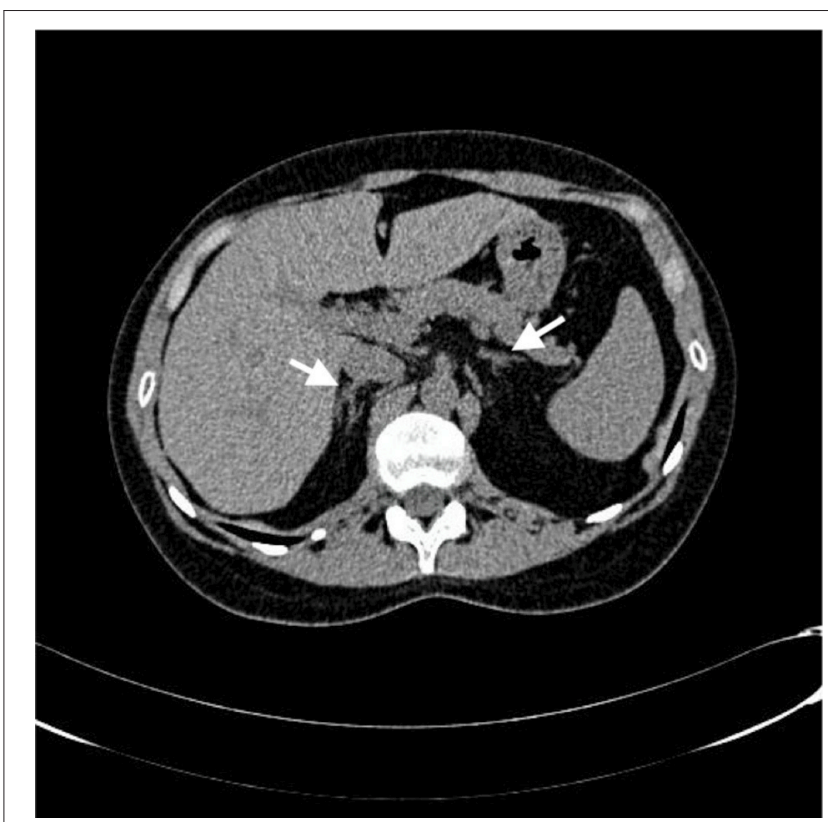

FIGURE 1 | Computed tomography scan showing normal adrenal glands.

intermittent variation of cortisol secretion. A primary pigmented nodular adrenocortical disease was suspected.

Before any further work-up or treatment a synthetic glucocorticoid serum screening was ordered. The administrators denied it due to the fact that this test was not available in our hospital. A positron emission tomography (PET)-CT using 18F-flurodeoxyglucose (18F-FDG PET/CT) did not show any uptake in the adrenal glands (Figure 2). She had no laboratory findings consistent with Carney complex. No cardiac myxomas were noted on echocardiogram. Thyroid ultrasound was normal. With the diagnosis of probable primary pigmented nodular adrenocortical disease a unilateral right adrenelectomy was performed. We planned a two-staged laparoscopic adrenal resection, with subsequent contralateral adrenelectomy in a delayed surgery once we had pathological confirmation of PPNAD. However, histopathological examination revealed normal adrenal gland. We decided to perform a synthetic glucocorticoid serum screen outside our hospital, which was sent to Mayo Clinic lab. High levels of serum prednisone and prednisolone $(2.9$ and $12 \mathrm{mcg} / \mathrm{dl}$, respectively-reference value $<0.1 \mathrm{mcg} / \mathrm{dl}$ ) performed by liquid chromatography-tandem mass spectrometry (LC-MS/MS) were found.

The psychiatrist at our hospital evaluated her. She was confronted with the evidence that her high steroid levels did not result from an endogenous production. She admitted taking steroids, prednisone $20 \mathrm{mg}$ per day. She was diagnosed with a dependent and histrionic personality disorder. Further questioning revealed her boyfriend died around 2 years previously due to a car accident. She has a suppressed hypothalamic-pituitary-adrenal (HPA) axis (early morning cortisol $<3 \mathrm{mcg} / \mathrm{dl}$ off glucocorticoid replacement for $24 \mathrm{~h}$ ) treated with hydrocortisone $10 \mathrm{mg}$ in the morning and $5 \mathrm{mg}$ in the afternoon. She is currently under psychiatric care. 


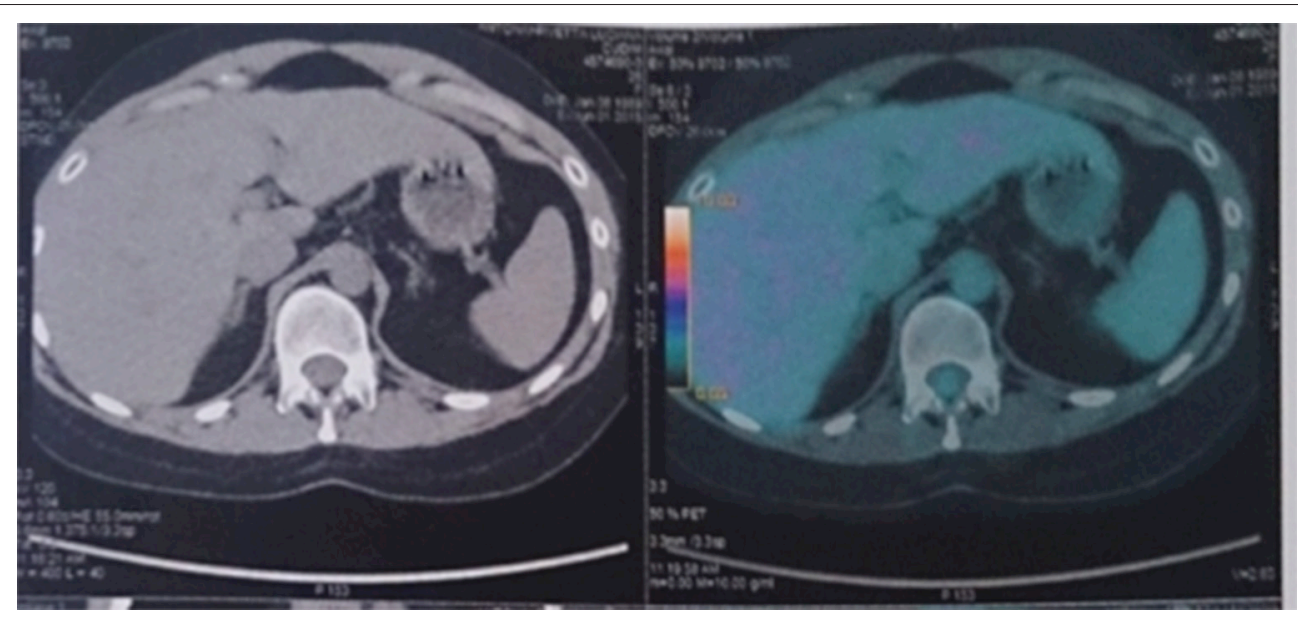

FIGURE 2 | 18F-FDG PET/CT scan showed no uptake in the adrenal glands.

TABLE 1 | Clinical and laboratory data from patients with unsuppressed ACTH.

\begin{tabular}{|c|c|c|c|c|c|c|c|}
\hline References & $\begin{array}{l}\text { Age } \\
\text { (Years) }\end{array}$ & Gender & Symptoms & $\begin{array}{l}\text { Plasma } \\
\text { ACTH }\end{array}$ & $\begin{array}{l}\text { Pituitary } \\
\text { MRI }\end{array}$ & $\begin{array}{l}\text { Adrenal CT } \\
\text { scan }\end{array}$ & Medication ingested \\
\hline Cizza et al. (5) & 44 & Female & Depression, fatigue, bone pain & Normal & Questionable & Normal & Not know \\
\hline Cizza et al. (5) & 37 & Female & Vertebral compression fractures & High & Microadenoma & Normal & $\begin{array}{l}\text { Prednisolone/ } \\
\text { dexamethasone }\end{array}$ \\
\hline Thynne et al. (4) & 54 & Female & $\begin{array}{l}\text { Weight gain, fatigue, easy bruising, } \\
\text { irritability, muscle weakness }\end{array}$ & Normal & Normal & Normal & Prednisolone \\
\hline Minanni et al. (6) & 26 & Female & $\begin{array}{l}\text { Depression, signs and symptoms of } \\
\text { Cushing's syndrome }\end{array}$ & Normal & Microadenoma & Normal & Prednisone \\
\hline
\end{tabular}

\section{DISCUSSION}

Despite the widespread use of glucocorticoids, there are few reported cases of factitious Cushing's syndrome. It represents $<1 \%$ of patients with Cushing's syndrome. At the National Institute of Health Clinical Centre they found 6 cases of factitious Cushing's syndrome in 860 patients evaluated for hypercortisolism (5). In this review patient characteristics of factitious Cushing's syndrome included an occupation related to the medical field or close contact with a medical worker, a history of anxiety or depression and several surgeries for unrelated disorders. In this case the brother works as a nurse, without any other of the features described previously.

There are 23 cases reported in the literature. Eighty two percent were female, with a mean age of 37 years old (416). Almost half (43\%) had a personal contact or occupation related to the medical field, and $57 \%$ history of psychiatric disorders. However, 4 cases presented with unsuppressed ACTH, which can mimic Cushing's disease (Table 1) (4-6). There are two fatal cases reported, due to pancreatitis and invasive aspergillosis $(6,15)$. To differentiate between endogenous and exogenous Cushing's syndrome may be difficult as physical findings are indistinguishable, and with similar psychiatric assessment (5). Differential diagnosis includes cyclic Cushing's, characterized by periodic fluctuations of cortisol secretion.
Cycles of hypercortisolism alternate with phases of normal or low cortisol production, which can last days or years (17). It can be present in ACTH dependent or independent Cushing's syndrome. Approximately in $10 \%$ of cases an adrenal tumor is the underlying cause (17). In this case, although there was a paradoxical increase of cortisol with a $100 \%$ rise in $24 \mathrm{~h}$ UFC during the Liddle's test suggestive of PPNAD, basal urine free cortisol levels were within normal values. It was interpreted as an intermittent variation of cortisol secretion, maybe due to cyclic Cushing's. The pathophysiology of cyclic Cushing's is unknown. Proposed mechanisms of cyclic Cushing's include episodic hemorrhage and/or necrosis of the tumor resulting in temporary damage of secreting cells as well as synchronous growth and death of ACTH- or cortisol- secreting tumor cells (18-21).

There are few cases of pigmented nodular adrenocortical disease presenting as cyclic Cushing's (22, 23). Primary pigmented nodular adrenocortical disease is rare, responsible for $<1 \%$ of Cushing's syndrome. The hipercortisolism is consequence of small-pigmented functioning nodules. Approximately $50 \%$ of cases are sporadic, the rest are familial ether isolated or as part of Carney complex (24). The paradoxical increase of UFC with dexamethasone during the Liddle's test is mediate by a glucocorticoid receptor overexpression in the nodules (25-27). Adrenal computed tomography is often 
interpreted as normal as the overall size of adrenal glands is not increased. However, the adrenal glands are occupied by small nodules that can be seen as string of beads on thin-section CT scan (24). Bandelin et al. reported a case in which PET-CT with $18 \mathrm{~F}$-flurodeoxyglucose showed uptake in both adrenal glands in a patient with PPNAD (28).

Laboratory features that suggest factitious Cushing's syndrome are erratic and fluctuating cortisol measurements as well as suppressed ACTH. In our case despite initial diagnosis of hypercortisolism with high UFC, during Liddle's test basal urine free cortisol levels were within normal values (71 $\mu \mathrm{g} /$ day).

Immunoassays measuring cortisol demonstrate crossreactivity with synthetic corticosteroids and their metabolites. Exogenous glucocorticoid ingestion may yield high cortisol levels depending on the degree of cross-reactivity, the timing of ingestion, and the patient's endogenous cortisol secretion (4). Synthetic glucocorticoids can be detected by LC-MS/MS, which is the most important tool to rule out factitious Cushing's syndrome. Hospitalization with observation of patient and search of the room may be helpful to reach a diagnosis, more so in this case that synthetic glucocorticoid screen was not available $(2,29)$.

In cases with ACTH-independent Cushing's that presents as cyclic Cushing's and normal adrenals on CT scan glucocorticoid screen may be an extreme valuable tool to prevent unnecessary work-up and treatments.

Moreover, systems with electronic medical records may be more helpful to diagnose factitious disorder compared to those with paper charts (30). Analysis of previous medical records through centralized databases may give access not only to records in the doctor's hospital system but also to hospital networks. It may be helpful for doctor's to know all prescriptions that the patient received. However, in this case the prednisone prescription was documented in the paper chart and was spontaneously referred by the patient.

The pathogenesis of factitious disorder is unknown. It has been associated with psychosocial factors such as early losses due to death, abandonment or sickness (31). In this case, after psychiatric consultation death of her boyfriend was noted. In addition, it has been associated with neurocognitive impairment, such as dysfunction of the right hemisphere (32). In some cases it has been also associated with personality disorders such as borderline personality disorder (31). Once diagnosed, psychiatric care is warranted. Treatment of factitious disorder is

\section{REFERENCES}

1. Grunberger G, Weiner JL, Silverman R, Taylor S, Gorden P. Factitious hypoglycemia due to surreptitious administration of insulin. Diagnosis, treatment, and long-term follow-up. Ann Intern Med. (1988) 108:252-7. doi: 10.7326/0003-4819-108-2-252

2. Keiser HR. Surreptitious self-administration of epinephrine resulting in 'pheochromocytoma'. JAMA. (1991) 266:1553-5. doi: 10.1001/jama.1991.03470110099040

3. Cohen JH III, Ingbar SH, Braverman LE. Thyrotoxicosis due to ingestion of excess thyroid hormone. Endocr Rev. (1989) 10:113-24. doi: $10.1210 /$ edrv-10-2-113 extremely difficult. Confrontation with the diagnosis often leads to denial, accusations, leave, and seek medical care elsewhere or threatens of lawsuits (33). Psychotherapy is the standard treatment, comparable to that for personality disorder (31).

In addition, replacement doses of steroids are necessary to address the secondary adrenal insufficiency due to suppression of the HPA axis that remains after long-term corticosteroid use. Sudden withdrawal of glucocorticoids should be avoided, and instructions for emergencies such as illness or surgery must be addressed. These patients may have increase morbidity and mortality associated with Cushing's syndrome (34). In our case, her symptoms and signs of Cushing's syndrome have disappeared. She lost weight and she is still under psychiatric care.

\section{CONCLUDING REMARKS}

In conclusion, factitious Cushing's syndrome represents a diagnostic challenge for physicians. It is an important diagnosis to consider in patients being evaluated for hypercortisolism. Discordant hormonal test results as well as normal findings on adrenal glands on CT scan should raise suspicion of this entity, and prompt measurement of synthetic corticosteroids using LC-MS/MS. In cases where synthetic glucocorticoid screen is not available and suspicion for factitious disorder is high hospitalization and waiting before sending the patient to surgery should be considered.

\section{ETHICS STATEMENT}

The patient provided written informed consent for research participation as well as for the publication of indirectly identifiable data (age, gender, and medical history).

\section{AUTHOR CONTRIBUTIONS}

MP wrote the first draft of the manuscript. LR contributed to the writing of the manuscript. MP, LR, SD, LS, EB, VB, and VE made contributions to the acquisition of the clinical data. MP, LR, SD, LS, EB, VB, VE, DC, and MV agreed with manuscript results and conclusions. MP and VE made critical revisions and approved final version. All the authors revised and approved the final manuscript and agreed to be accountable for the content of the work.
4. Thynne T, White GH, Burt MG. Factitious Cushing's syndrome masquerading as Cushing's disease. Clin Endocrinol. (2014) 80:328-32. doi: 10.1111/cen.12343

5. Cizza G, Nieman LK, Doppman JL, Passaro MD, Czerwiec FS, Chrousos GP, et al. Factitious Cushing syndrome. J Clin Endocrinol Metabol. (1996) 81:3573-7.

6. Minanni CA, Albuquerque EVA, Lopes LML, Glezer A, Galluccineto J, Gattaz WF, et al. Fatal factitious Cushing syndrome (Münchhausen's syndrome) in a patient with a prolactinoma and silent corticotrophinoma: case report and literature review. J Women's Health Care. (2014) 3:4. doi: 10.4172/2167-0420.10 00162 
7. Witt ME, Ginsberg-Fellner F. Prednisone-induced Munchausen syndrome. Am J Dis Child. (1981) 135:852-3. doi: 10.1001/archpedi.1981.02130330062020

8. Cook DM, Meikle AW. Factitious Cushing's syndrome. J Clin Endocrinol Metabol. (1985) 61:385-7. doi: 10.1210/jcem-61-2-385

9. O'Hare JP, Vale JA, Wood S, Corrall RJ. Factitious Cushing's syndrome. Acta Endocrinol. (1986) 111:165-7. doi: 10.1530/acta.0.1110165

10. Anderson PW, Galmarini M, Vagnucci A, Horton R. Factitious Cushing's disease. Western J Med. (1993) 159:487-9.

11. O'Shaughnessy IM, Raff H, Findling JW. Factitious Cushing's syndrome: discovery with use of a sensitive immunoradiometric assay for corticotropin. Endocr Pract. (1995) 1:327-9. doi: 10.4158/EP.1.5.327

12. Workman RJ, Nicholson WE, McCammon DK. Factitious hypercortisoluria. $J$ Clin Endocrinol Metabol. (1995) 80:3050-1.

13. Villanueva RB, Brett E, Gabrilove JL. A cluster of cases of factitious Cushing's syndrome. Endocr Pract. (2000) 6:143-7. doi: 10.4158/EP.6.2.143

14. Ach K, Khochtali I, Ajmi ST, Beizig AM, Chadli MC, Ajina MZ, et al. Factitious Cushing syndrome: two case reports. Rev Med Intern. (2005) 26:973-6. doi: 10.1016/j.revmed.2005.07.011

15. Kansagara DL, Tetrault J, Hamill C, Moore C, Olson B. Fatal factitious Cushing's syndrome and invasive aspergillosis: case report and review of literature. Endocr Pract. (2006) 12:651-5. doi: 10.4158/EP.12.6.651

16. Kline GA, Buse JD, Van Der Gugten JG, Holmes DT, Chin AC, Sadrzadeh SMH. Factitious ACTH-dependent, apparent hypercortisolism: the problem with late-night salivary cortisol measurements collected at home. Clin Endocrinol. (2017) 87:882-5. doi: 10.1111/cen.13478

17. Zerikly RK, Eray E, Faiman C, Prayson R, Lorenz RR, Weil RJ, et al. Cyclic Cushing syndrome due to an ectopic pituitary adenoma. Nat Clin Pract Endocrinol Metabol. (2009) 5:174-9. doi: 10.1038/ncpendmet1039

18. Meinardi JR, Wolffenbuttel BH, Dullaart RP. Cyclic Cushing's syndrome: a clinical challenge. Eur J Endocrinol. (2007) 157:245-54. doi: 10.1530/EJE-07-0262

19. Mantero F, Scaroni CM, Albiger NM. Cyclic Cushing's syndrome: an overview. Pituitary (2004) 7:203-7. doi: 10.1007/s11102-005-4025-5

20. Thorner MO, Martin WH, Ragan GE, MacLeod RM, Feldman PS, Bruni C, et al. A case of ectopic ACTH syndrome: diagnostic difficulties caused by intermittent hormone secretion. Acta Endocrinol. (1982) 99:364-70. doi: 10.1530/acta.0.0990364

21. Schweikert HU, Fehm HL, Fahlbusch R, Martin R, Kolloch R, Higuchi M, Kruck F. Cyclic Cushing's syndrome combined with cortisol suppressible, dexamethasone non-suppressible ACTH secretion: a new variant of Cushing's syndrome. Acta Endocrinol. (1985) 110:289-95. doi: 10.1530/acta.0.110 0289

22. Carson DJ, Sloan JM, Cleland J, Russell CF, Atkinson AB, Sheridan B. Cyclical Cushing's syndrome presenting as short stature in a boy with recurrent atrial myxomas and freckled skin pigmentation. Clin Endocrinol. (1988) 28:173-80. doi: 10.1111/j.1365-2265.1988.tb03653.x

23. Gunther DF, Bourdeau I, Matyakhina L, Cassarino D, Kleiner DE, Griffin $\mathrm{K}$, et al. Cyclical Cushing syndrome presenting in infancy: an early form of primary pigmented nodular adrenocortical disease, or a new entity? J Clin Endocrinol Metabol. (2004) 89:3173-82. doi: 10.1210/jc.2003-032247
24. Lacroix A, Bourdeau I. Bilateral adrenal Cushing's syndrome: macronodular adrenal hyperplasia and primary pigmented nodular adrenocortical disease. Endocrinol Metabol Clin North Am. (2005) 34:441-58. doi: 10.1016/j.ecl.2005.01.004

25. Louiset E, Stratakis CA, Perraudin V, Griffin KJ, Libe R, Cabrol $\mathrm{S}$, et al. The paradoxical increase in cortisol secretion induced by dexamethasone in primary pigmented nodular adrenocortical disease involves a glucocorticoid receptor-mediated effect of dexamethasone on protein kinase A catalytic subunits. J Clin Endocrinol Metabol. (2009) 94:2406-13. doi: 10.1210/jc.2009-0031

26. Stratakis CA, Sarlis N, Kirschner LS, Carney JA, Doppman JL, Nieman LK, et al. Paradoxical response to dexamethasone in the diagnosis of primary pigmented nodular adrenocortical disease. Ann InternMed. (1999) 131:58591. doi: 10.7326/0003-4819-131-8-199910190-00006

27. Bourdeau I, Lacroix A, Schurch W, Caron P, Antakly T, Stratakis CA. Primary pigmented nodular adrenocortical disease: paradoxical responses of cortisol secretion to dexamethasone occur in vitro and are associated with increased expression of the glucocorticoid receptor. J Clin Endocrinol Metabol. (2003) 88:3931-7. doi: 10.1210/jc.2002-022001

28. Bandelin PB, Moreno AJ, Lemar HJ, Stratakis CA, Oliver TG. The use of positron emission tomography-computed tomography scan in the evaluation of a patient with Carney complex. J Clin Endocrinol Metabol. (2008) 93:29467. doi: 10.1210/jc.2008-0313

29. Spitzer D, Bongartz D, Ittel TH, Sieberth HG. Simulation of a pheochromocytoma-Munchausen syndrome. Eur J Med Res. (1998) 3:549-53.

30. Van Dinter TG Jr, Welch BJ. Diagnosis of Munchausen's syndrome by an electronic health record search. Am J Med. (2009) 122:e3. doi: 10.1016/j.amjmed.2009.03.035

31. Bass C, Halligan P. Factitious disorders and malingering: challenges for clinical assessment and management. Lancet. (2014) 383:1422-32. doi: 10.1016/S0140-6736(13)62186-8

32. Pankratz L, Lezak MD. Cerebral dysfunction in the Munchausen syndrome. Hillside J Clin Psychiatry. (1987) 9:195-206.

33. Eastwood S, Bisson JI. Management of factitious disorders: a systematic review. Psychother Psychosomat. (2008) 77:209-18. doi: 10.1159/000126072

34. Nieman LK, Biller BM, Findling JW, Newell-Price J, Savage MO, Stewart $\mathrm{PM}$, et al. The diagnosis of Cushing's syndrome: an Endocrine Society Clinical Practice Guideline. J Clin Endocrinol Metabol. (2008) 93:1526-40. doi: $10.1210 /$ jc.2008-0125

Conflict of Interest Statement: The authors declare that the research was conducted in the absence of any commercial or financial relationships that could be construed as a potential conflict of interest.

Copyright $\odot 2019$ Pineyro, Redes, De Mattos, Sanchez, Brignardello, Bianchi, Ems, Centurión and Viola. This is an open-access article distributed under the terms of the Creative Commons Attribution License (CC BY). The use, distribution or reproduction in other forums is permitted, provided the original author(s) and the copyright owner(s) are credited and that the original publication in this journal is cited, in accordance with accepted academic practice. No use, distribution or reproduction is permitted which does not comply with these terms. 